\title{
A ALIMENTAÇÃO E SEU LUGAR NA HISTÓRIA: OS TEMPOS DA MEMÓRIA GUSTATIVA
}

\author{
Feeding and its place in history: the gustatorial \\ memory period
}

\author{
Carlos Roberto Antunes dos Santos*
}

\begin{abstract}
RESUMO
O texto trata do estado da arte relativo ao tema da História da Alimentação, destacando os conceitos, fundamentos e referenciais teórico-metodológicos colocados em evidência por meio de uma importante base historiográfica, com obras, textos e projetos de pesquisa que apontam o lugar da alimentação na História.
\end{abstract}

Palavras-chave: memória gustativa, categoria histórica, comida.

\section{ABSTRACT}

The present text is about the state of the art related to the theme of Food History that brings out the concepts, foundations and theoreticalmethodological references that are highlighted through an important historiographic basis, with works, texts, and research projects that indicate the location of the food in the history.

Key-words: tasting memory, historic category, food.

O tema da alimentação, finalmente, começa a invadir a História, impulsionando maior diálogo multi, inter e transdisciplinar e fazendo com que as editoras invistam cada vez mais nessa área, transformando em best-sellers até mesmo simples manuais de receitas culinárias. As pesquisas acadêmicas - muitas que redundaram em dissertações e teses de pós-graduação - que abrangem processos históricos com enfoque social, cultural, econômico, político, tecnológico, nutricional ou antropológico, e mesmo como monografias

* Professor Titular em História do Brasil da UFPR. 
sobre determinados alimentos, buscam recuperar os tempos da memória gustativa, possibilitando as desejáveis articulações entre a História e outras disciplinas. Os sucessos editoriais nos domínios da História da Alimentação revelam duas grandes paixões do público consumidor: o gosto pela História e pela gastronomia.

A presente comunicação tem por objetivo dar notícias e informações sobre as tendências mais recentes da historiografia contemporânea a respeito da História da Alimentação, destacando algumas obras (dentre outras) consideradas de real importância, que possam constituir um inventário, um certo estado da arte pertinente ao tema, numa breve e não exaustiva revisão da literatura. A maioria das obras aqui relacionadas é classificada cronologicamente em função do período de suas publicações no Brasil e abarca análises gerais, isto é, a história da comida e da alimentação pelo mundo desde os primórdios, a partir de distintos enfoques. As outras obras apresentadas constituem monografias sobre determinados alimentos, para vastos panoramas históricos.Tal revisão estará centrada em obras nacionais e estrangeiras, já traduzidas e publicadas no Brasil, o que revela o interesse editorial pelo assunto. Na outra ponta, após a apresentação da revisão bibliográfica, daremos notícias acerca dos textos que compõem este dossiê sobre a História da Alimentação.

Há, hoje, uma obsessão pela história da mesa, fazendo com que a gastronomia saia da cozinha e passe a ser objeto de estudo com a devida atenção ao imaginário, ao simbólico, às representações e às diversas formas de sociabilidade ativa. Neste sentido, a questão da alimentação deve se situar no centro das atenções dos historiadores e de reflexões sobre a evolução da sociedade, pois a História é a disciplina que oferece um suporte fundamental e projeta perspectivas.

As cozinhas locais, regionais, nacionais e internacionais são produtos da miscigenação cultural, fazendo com que as culinárias revelem vestígios das trocas culturais. Hoje, os estudos sobre a comida e a alimentação invadem as Ciências Humanas a partir da premissa de que a formação do gosto alimentar não se dá, exclusivamente, pelo seu aspecto nutricional, biológico. $\mathrm{O}$ alimento constitui uma categoria histórica, pois os padrões de permanência e mudanças dos hábitos e práticas alimentares têm referências na própria dinâmica social. Os alimentos não são somente alimentos. Alimentar-se é um ato nutricional, comer é um ato social, pois constitui atitudes ligadas aos usos, costumes, protocolos, condutas e situações. Nenhum alimento que entra em nossas bocas é neutro. A historicidade da sensibilidade gastronômica explica e é explicada pelas manifestações culturais e sociais como espelho de uma época e que 
marcaram uma época. Neste sentido, o que se come é tão importante quanto quando se come, onde se come, como se come e com quem se come. Enfim, este é o lugar da alimentação na História.

A abrangência do tema da alimentação é tão ampla que, na França, o Ministério da Educação criou, recentemente, o Instituto do Gosto, da Gastronomia e da Arte à Mesa, enquanto que, na Itália, o movimento "SlowFood" inaugurou a Universidade de Ciências Gastronômicas, destacando aí a História da Cozinha e da Gastronomia. Portanto, surgiram, na França e na Itália, em 2004, universidades da Comida e da História da Alimentação.

Do exposto, constata-se que a História da Alimentação, que foi por muito tempo ignorada, principalmente pela historiografia brasileira, demonstra agora a sua vitalidade, pois diz muito sobre a educação, a civilidade e a cultura dos indivíduos.

Entretanto, durante muito tempo, a alimentação e as práticas culinárias constituíram-se em espaços privilegiados de estudos da Antropologia e dos antropólogos. As portas começaram a ser abertas para a historiografia com a divulgação de duas obras pioneiras: A fisiologia do gosto, de Brillat-Savarin, escrita em 1825, que trata do homem e da comida, pois não se constitui num livro de culinária, mas sim de gastronomia; e o trabalho do botânico polonês Adam Maurizio, intitulado História da alimentação vegetal da pré-história aos nossos dias, publicado em Paris em 1932, no qual o autor procurou estabelecer um elo entre a história dos vegetais e a história das civilizações. A tese de E. Labrousse sobre o movimento da produção e a curva de preços na França ao longo do século XVIII (com base nas mercuriales) foi pioneira, no campo da História Econômica e Social, ao revelar a questão da penúria e da carestia dos preços do trigo e de outros cereais, crise esta que veio somar-se a outras crises de natureza política, social e institucional cujo conjunto contribuiu para a eclosão da Revolução Francesa. Portanto, além das peripécias dos Estados Gerais na França, a baixa oferta de cereais e a conseqüente elevação dos preços do trigo foram reveladores da explosão revolucionária de 1789 , que derrubou o Antigo Regime. Entretanto, foi com F. Braudel, herdeiro de Febvre e Bloch, por meio dos conceitos de cultura material, que a História da Alimentação ganhou fisionomia definitiva no campo da pesquisa histórica. Inspirado nos textos de Lucien Febvre sobre a distribuição regional das gorduras e nos fundos de cozinha, Braudel, como o maior representante da segunda geração dos Annales, trabalhou o conceito de cultura material abrangendo os aspectos mais imediatos da sobrevivência humana: a comida, a habitação e o vestuário. 
Em 1974, o lançamento da coletânea Faire de l'histoire, traduzida no Brasil como História: novos problemas, novas abordagens, novos objetos, trouxe à tona novos paradigmas da História. Na apresentação dessa coletânea, seus organizadores, Jacques Le Goff e Pierre Nora, reivindicavam para a nova História "a coexistência de vários tipos de história igualmente válidos" e defendiam o fatiamento da História, a microhistória, em contraposição a uma história absoluta do passado. Historiadores como Jean Paul Aron e Jean Louis Flandrin deslocam o foco da história em migalhas para o comer e para aquele que come. Por meio desses novos paradigmas, os ensinamentos dos Annales, a comida deveria ser levada a sério pelos historiadores.

Desta forma, a história do cotidiano e das mentalidades vai dar consistência aos estudos da sensibilidade alimentar, do gosto, da gastronomia. A partir do final dos anos 70, multiplicaram-se os estudos que se dedicaram às práticas alimentares dos indivíduos em contextos e períodos históricos diferentes. Destaca-se a obra de Jean-François Revel, Um banquete de palavras, traduzida e publicada no Brasil em 1996, na qual o autor persegue as duas faces da gastronomia - a popular e a erudita - e revela que as grandes fontes da história da sensibilidade gastronômica são a literatura e a arte. Nesse sentido, para Revel, a cozinha é arte desde que se considere a representação dos sabores. A cozinha, para o autor, é o universo onde convivem intuição, sensibilidade, imaginação e criatividade, permitindo múltiplas dimensões e integrações. Entretanto, o autor afirma que a cozinha é também um espaço de desaparecimentos, de perdas e destruições.

Ao buscar reconstituir a história da mentalidade e do gosto, Piero Camporesi, na obra Hedonismo e exotismo, publicada no Brasil em 1996, localiza no Século das Luzes o rompimento com o modo tradicional de se alimentar e o determina como o período em que se dá a descoberta da noite. Para o autor, o tabu da noite foi quebrado pelo Iluminismo, passando a ser um tempo social, surgindo o prazer de consumir o tempo por meio de conversas em torno de uma mesa de alimentos. Para Camporesi, acontece "a substituição do tempo da natureza pelo tempo da cultura", em que "nascia uma nova, uma terceira cozinha ao lado de duas antigas e clássicas, a nobre e a popular", triunfando "uma cozinha do olhar, dirigida aos espíritos mais leves e requintados".

Destaque deve ser debitado ao texto A História da Alimentação: balizas historiográficas, dos professores Ulpiano T. Bezerra de Meneses e Henrique Carneiro, publicado em 1997, no qual buscaram, a partir da noção de campo de referências, problemas e interações próprias da multi e da interdisciplinaridade, caracterizar o campo de estudo da História da Alimentação. Para os autores, esse 
campo se encontra em processo de consolidação e o trabalho que apresentam traça esse perfil, respaldado por uma interessante, exaustiva e rigorosa análise historiográfica, bem como por um quadro mais diverso de disciplinas ligadas ao universo da alimentação. Contemporâneo a esse trabalho é o texto de minha autoria, intitulado Por uma História da Alimentação, publicado em 1997, no qual, além de apontar algumas das possibilidades de pesquisa emanadas do tema da gastronomia, apresento a tese de que a formação do gosto alimentar não é, exclusivamente, determinado pelos valores nutricionais, biológicos. Concorrem aí também as mentalidades, os ritos, o valor das mensagens que se trocam quando se está diante da mesa e da comida, os valores éticos e religiosos, a transmissão inter e intrageração, a psicologia individual e coletiva e outros tantos fatores. Desta forma, o alimento constitui uma categoria histórica, pois os padrões de permanências e mudanças dos hábitos e práticas alimentares em ritmos diferenciados têm referências na própria dinâmica social.

Os hábitos e práticas alimentares de grupos sociais, práticas estas distantes ou recentes que podem vir a constituírem-se em tradições culinárias, fazem, muitas vezes, com que o indivíduo se considere inserido num contexto sociocultural que lhe outorga uma identidade, reafirmada pela memória gustativa. Tal reflexão encontra guaridas explicativas na obra $A$ invenção das tradições, organizada por E. Hobsbawm e E. Ranger, com a segunda edição publicada em português, em 1997, a qual permite suporte teórico à questão das tradições culinárias.

No tocante ao tema da etiqueta e das boas maneiras à mesa, o livro de Margaret Visser, $O$ ritual do jantar, traduzido e publicado no Brasil no ano de 1998, constitui uma referência. Segundo a autora, o homem transforma o consumo do alimento, que é uma necessidade biológica, numa necessidade cultural, usando o ato de comer como um veículo para relacionamentos sociais. Daí percebe-se, instigado por Visser, a presença de uma série de mecanismos de diferenciação, integração e distinção social em relação às regras que envolvem o ato de alimentar-se, ou seja, é necessário estar munido de conhecimentos a respeito de regras de boas maneiras à mesa para que assim seja garantida a inclusão social.

$\mathrm{O}$ conhecimento da alimentação e da gastronomia, no tocante à educação, à civilidade, à cultura e ao comportamento, é tratado na obra $D e$ caçador a gourmet - uma história da gastronomia, de Ariovaldo Franco, publicada em 2001. O texto é dividido em fatias cronológicas, ainda que os processos sociais não sejam estanques ou limitados, com destaques às cozinhas nacionais e regionais, mas principalmente aquelas de referência. 
A revelação da cozinha como um microcosmo da sociedade, com todo o significado simbólico na construção de regras e sistemas alimentares, impregnada de cultura, é tratada na obra Comida e sociedade: uma história da alimentação, de Henrique Carneiro, publicada em 2003. No livro, o autor, dentre outros, sugere aos historiadores direções no campo da História da Alimentação, segundo as perspectivas das Ciências Humanas, que possam revelar a estrutura da vida cotidiana a partir do universo da comida. Há, inclusive, um capítulo dedicado à historiografia da alimentação no Brasil.

Teses consagradas que atribuíram à Revolução Francesa o privilégio de constituir-se no estopim do crescimento dos restaurantes em Paris e explicaram a arte culinária como uma das grandes conquistas da revolução são contestadas pela inglesa Rebecca L. Spang, no livro $A$ invenção dos restaurantes, lançado no Brasil em novembro de 2003. Essa vertente da História da Alimentação, no tocante ao tema monográfico, no caso, sobre o restaurante, assume amplos horizontes nesse estudo. A autora defende a tese de que os restaurantes foram originários de pequenos estabelecimentos como "casas de saúde", onde se vendia uma sopa restauradora (bouillon restaurant) para pessoas fracas ou debilitadas do peito. Nessas casas, o caldo revigorante era o restaurador das forças, o "restaurant", que, por extensão, acabou dando nome a esses estabelecimentos.

Ainda no tocante aos temas monográficos da História da Alimentação, o trabalho de Heinrich E. Jacob, sobre Seis mil anos de pão: a civilização humana através do seu principal alimento, datado de 1944 e recentemente publicado no Brasil, conta como a história do pão se confunde com a própria trajetória da civilização ocidental: o trigo cultivado no Egito, que produziu a padaria artística, a presença do pão entre os gregos, considerados como os melhores padeiros da antiguidade, e os romanos, que fizeram dele um instrumento de suas políticas de conquistas e de manutenção da ordem no vasto Império. Considerando ainda a presença deste alimento entre os judeus e os cristãos, o autor identifica no pão elementos simbólicos, de representação, de expressão religiosa e manifestação cultural. Por meio da história do pão, o autor busca detectar os fios de uma rede de sentidos múltiplos que demarcam, diferenciam e retiram do silêncio determinados processos históricos, como se procedessem de diversas escritas.

Um livro importante, que veio à luz em 2004, trata da Comida: uma história, do historiador Felipe Fernández-Armesto. Nesse livro, o autor pretende demonstrar que a história da comida é tão cultural quanto a história da culinária. Lamentando a negligência da maioria das instituições acadêmicas 
com a história da comida e a diversidade de abordagens dos historiadores, que dificulta a sua síntese, o autor considera que a rapidez com que surgem novos materiais faz com que seja mais difícil a atualização satisfatória por meio de revisões periódicas. Adotando uma perspectiva global, Fernández-Armesto trata a comida como um tema da história mundial, a partir de oito grandes revoluções, desde a invenção da culinária, passando pelo significado do ato de comer, contemplando a utilização da vida vegetal como alimento, até a comida e a industrialização nos séculos XIX e XX, que, combinadas, parecem fornecer uma visão geral de toda a história da alimentação.

Ainda em termos de obras monográficas, mas com amplas dimensões, temos o livro de Mark Kurlansky, intitulado Sal: uma história do mundo, publicado no Brasil em 2004. Para o autor, o sal está presente em quase todos os lugares e, durante milênios, foi sinônimo de riquezas: pelo sal, criaram-se rotas comerciais, firmaram-se impérios e provocaram-se revoluções, sendo também um instrumento comum de comércio e câmbio. Como o sal está presente no nosso cotidiano, sua dimensão é universal e Kurlansky busca, ao estudar o sal, perseguir e explicar a história da humanidade. Assim como na história do pão, já referenciada acima, a história do sal é impregnada de simbolismo, de superstições, de tabus, de representações culturais, de símbolos metafóricos de todas as religiões.

Uma obra geral de grande evidência e referência, constituindo uma publicação coletiva denominada História da Alimentação, sob a direção de Jean-Louis Flandrin e Massimo Montanari, ofereceu um balanço das pesquisas que vinham sendo realizadas pelos historiadores sobre o tema, propondo caminhos e métodos de investigação. Seu aparecimento trouxe novos impulsos e estímulos aos estudos da História da Alimentação. Na base da obra, estão a preocupação com as estruturas do cotidiano, suas historicidades explicadas pela comida e inseridas na longa duração Braudeliana.

O volume da produção historiográfica que trata da História da Alimentação no Brasil é ainda muito pobre, comparado com o ativo mercado editorial nos países europeus, cujos principais historiadores estão filiados ao Instituto Europeu de História da Alimentação - IEHA -, do qual participam também pesquisadores dos EUA, Canadá, México, Brasil, Austrália e Israel.

No Brasil, o destaque provém da imensa obra de Luís da Câmara Cascudo, a mais completa no tema, em que se sobressai, em dois volumes e publicado em 1967, A História da Alimentação no Brasil: cardápio indígena, dieta africana, ementa portuguesa, e cozinha brasileira. Nessa obra, Câmara Cascudo, sociólogo e folclorista brasileiro, afirma "que todos os grupos 
humanos tem uma fisionomia alimentar. A fidelidade ao paladar, fixado através de séculos na continuidade alimentar é uma permanente tão arraigada que já pode ser biológica". As dádivas sob a forma de comida sempre tiveram um papel importante nas sociedades tradicionais para estabelecer e/ou reforçar os laços de solidariedade no conjunto da comunidade. Para Câmara Cascudo, "em momentos rituais ou cerimoniais o alimento é um elemento fixador psicológico no plano emocional e comer certos pratos é ligar-se ao local ou a quem o preparou". Há, na obra, uma evidente tentativa de construção das especificidades regionais, a partir de fontes históricas e etnográficas, dentro de um quadro sociológico, cujo objetivo maior é de caracterizar a alimentação no Brasil colonial a partir dos alimentos nativos.

Dentre as obras de Gilberto Freyre, podemos destacar o Açúcar, de 1939, a qual oferece grande contribuição para o entendimento da identidade nacional a partir da civilização do açúcar no Brasil - a sacarocracia -, cujo tema passa pela História, Sociologia, Antropologia e pela Economia, marcando decisivamente as práticas e hábitos alimentares no Brasil. O saber culinário em formas de receitas, transmitido de mãe para filha, muitas vezes encerrando segredos culinários, constitui para Freyre uma espécie de "maçonaria das mulheres".

Entendendo que a comida desperta lembranças que permitem reconstruir a memória, o que possibilita redefinir e reconstruir identidades, temos o importante texto de Roberto da Matta, Sobre o simbolismo da comida no Brasil, publicado em 1987. Da Matta afirma que "a comida tem o papel de destacar identidades e, conforme o contexto das refeições elas podem ser nacionais, regionais, locais, familiares ou pessoais".

A obra A História da Alimentação no Paraná, de minha autoria e publicada em 1995, trata do estudo de uma sociedade rural e de suas estruturas agrárias, caracterizando também o universo dos produtos de subsistência, produção e abastecimento. É um trabalho que, a partir da História Econômica, busca entender o cotidiano da alimentação e dos elementos que concorrem para a formação do gosto alimentar, considerando os contextos históricos.

Destacando os pratos e as receitas mais populares e importantes de cada região, o livro Cozinha brasileira (com recheio de história), de autoria do historiador Ivan Alves Filho e de um mestre em culinária, Roberto di Giovanni, publicado em 2000, trata de dar historicidade às cozinhas locais e regionais: para cada prato, uma história. Os autores buscam explicar os prazeres da mesa estabelecendo, de forma ousada, "uma espécie de reverso da medalha da 
colonização (não mais a Europa no Brasil, mas o Brasil se reencontrando com seu passado e influenciando a própria trajetória européia)".

A produção historiográfica do grupo de pesquisa em História da Alimentação, inserido na linha de pesquisa "Cultura e poder" e vinculado aos cursos de graduação e pós-graduação em História da UFPR, deve ser considerada. O grupo, sob a minha coordenação, produziu, em seis anos, cinco teses de doutorado e seis dissertações de mestrado, algumas já publicadas, e há ainda mais duas defesas de teses de doutorado agendadas para o final de 2004. Tal acervo guarda os seguintes estudos e projetos: Vida material, vida econômica; $A$ arca do sabor: a preservação do patrimônio gustativo da sociedade curitibana; Hábitos alimentares e cadernos de receitas: comensalidade e transmissão; Os bares e restaurantes de Curitiba como espaços de sociabilidade ativa; $A$ Padaria América e o pão das gerações curitibanas; A formação do padrão alimentar em Curitiba; $A$ arte de receber: distinção e poder à boa mesa; Do cru ao assado: a festa do boi assado no rolete de Marechal Cândido Rondon (a invenção das tradições); Do gosto e do afeto: comida de imigrantes em Curitiba; Do privado ao público: o universo do Restaurante Bolonha; O Brasil à mesa: história, literatura e sensibilidade gastronômica; Alimentação e saúde em Curitiba: o desequilíbrio dietético e a obesidade infantil; Terra, cultura e poder: a trajetória do Visconde de Guarapuava; Saúde, felicidade e leite: hábitos e práticas alimentares infantis no Brasil; Das casas de pasto aos restaurantes em Curitiba; Tradições culinárias de imigrantes/descendentes de alemães em Curitiba: memória e identidade; A transição histórica da cozinha clássica para a "nouvelle cuisine"; Festas gastronômicas como espaços turísticos/ culturais (a tradição inventada); Bar Palácio: gastronomia, intelectualidade e boemia em Curitiba; $A$ história da polenta como expressão gastronômica da imigração italiana; $O$ doce sabor oferecido pela Confeitaria das Famílias; $A$ História do Mercado Municipal, entre outros.

Ainda em termos de produção brasileira, cumpre destacar o número 33 da revista Estudos Históricos, da Fundação Getúlio Vargas, publicado no primeiro semestre de 2004, dedicado à alimentação e apresentando temas como: "Culinária de papel"; "Uma cozinha à brasileira"; "A fome e o paladar: a antropologia nativa de Luís da Câmara Cascudo"; "Cachaça, vinho e cerveja: da Colônia ao século XX"; "Cozinhar e comer, em casa e na rua: culinária e gastronomia na corte do Império do Brasil"; "Imigrantes, criollos e a alimentação porteña: Buenos Ayres, final do século XIX e início do século XX"; "Restaurantes de comida rápida, os fast-foods, em praças de alimentação de shopping centers: transformações no comer"; "Comer como atividade de 
lazer". Tais textos se enquadram nos estudos que têm a alimentação como objeto histórico.

Uma obra bastante significativa apareceu traduzida para o português no ano de 2004, de autoria de Roy Strong, Banquete: uma história ilustrada da culinária, dos costumes e da fartura à mesa. Nesse trabalho, o autor analisa cinco milênios de refeições cerimoniais, procurando demonstrar como os costumes que cercam as grandes refeições refletem de maneira privilegiada a estrutura social. A obra abarca a culinária de gala, etiqueta, maneiras à mesa, mobiliário, tecidos, cerâmica, vidraria, talheres, arquitetura, decoração e música. O autor traça uma longa história, passando pelo symposion grego, a festa medieval, o banquete renascentista e o jantar festivo contemporâneo.

Recentemente, foi lançada a obra do professor Henrique Carneiro, da Universidade de São Paulo, intitulada Pequena enciclopédia da história das drogas e bebidas. O livro trata, de forma inédita, do papel das drogas, das bebidas e dos alimentos de propriedades psicoativas, de extrema importância econômica, política e cultural, particularmente na História Moderna. A obra apresenta mais de 150 verbetes, contando uma história que abrange tanto os aspectos históricos quanto científicos de substâncias comuns (tabaco, café, vinho), proibidas (LSD, cocaína, ectasy) e curiosas (bangüê, bétel, ayahuasca).

Ainda em termos de lançamento, recentemente surgiu a coletânea de textos de autoria de Dias Lopes, intitulada $A$ canja do imperador. O livro reúne um conjunto de 74 crônicas sobre os desejos culinários, aromas e sabores de diversas personalidades, desde as refeições reais, isto é, das mesas dos imperadores Dom Pedro I e Dom Pedro II, às preferências de famosos gourmets, dentre outros, como o estadista Taylerand, Churchill, Balzac, Casanova, Portinari, Hemingway, Freud, John Kennedy, Grace Kelly, Carmen Miranda e a musa do cinema Marilyn Monroe. Aborda ainda famosos cozinheiros, como Carême e Scappie, e diversas outras personalidades, destacando o jogador Leônidas da Silva, que batizou o chocolate Diamante Negro, da Lacta.

O campo da História da Alimentação é extremamente rico de possibilidades temáticas que se oferecem ao historiador da cultura e a outros profissionais, como aqueles da área da Nutrição, contemplando a culinária, a alimentação e seus rituais de comensalidade, bem como as práticas alimentares.

Do exposto, a História da Alimentação, ocupando o seu lugar na História, busca estudar as preferências alimentares, a significação simbólica dos alimentos, as proibições dietéticas e religiosas, os hábitos culinários, a 
etiqueta e o comportamento à mesa e, de maneira geral, as relações que a alimentação mantém em cada sociedade com os mitos, a cultura e as estruturas sociais, ao sabor dos processos históricos.

$\mathrm{Na}$ cozinha, prevalece a arte de elaborar os alimentos e de lhes dar sabor e sentido. Nela, há a intimidade familiar, os investimentos afetivos, simbólicos, estéticos e econômicos. Em seu interior, despontam as relações de gênero, de geração, a distribuição das atividades que traduzem uma relação de mundo, um espaço rico em relações sociais, fazendo com que a mesa se constitua, efetivamente, num ritual de comensalidade. A cozinha é, portanto, um espelho da sociedade, um microcosmo da sociedade, é a sua imagem. Em vez de falar em cozinha, é melhor falar em cozinhas, no plural, porque elas mudam, transformam-se graças às influências e aos intercâmbios entre as populações, graças aos novos produtos e alimentos, graças às circulações de mercadorias.

Desta forma, sendo um microcosmo da sociedade, a cozinha abrange desde a produção de pratos tradicionais, conforme a produção literária já elencada anteriormente, passando pela nouvelle cuisine e chegando à cozinha compartimentada, característica do fast-food, dos "McDonald's da vida". Essa cozinha dos fast-foods, do McDonald's, é filha das mudanças desencadeadas desde a metade do século passado até os dias de hoje. Vivemos, hoje, a MacDonaldização do mundo, prevalecendo um gosto pasteurizado e homogêneo, sem graça.

Diante das transformações impressas pela urbanização e pela globalização, a alimentação passou e continua passando por mudanças que afetam a qualidade dos alimentos produzidos e industrializados. Na verdade, um novo estilo de vida impõe novas expectativas de consumo, que acabam orientando as escolhas de alimentos. Para Hobsbawm, na obra $A$ era dos extremos, nesta transição de final e início de milênio, há o triunfo do indivíduo sobre a sociedade, ou melhor, o rompimento dos fios que antes ligavam os seres humanos em texturas sócias. É o estilo jovem de vida que triunfa, estilo este que passou a ser marca mundial, isto é, a juventude praticamente deixa de ser uma etapa da vida para se constituir num estilo de vida. O jeans, o rock, o hambúrguer e a Coca-Cola são expressões simbólicas dessa nova cultura. Os adolescentes ganharam maior autonomia e isso é vislumbrado pela indústria, que vê aí um mercado promissor. Daí as mudanças dos padrões, que parecem menos satisfatórios ao paladar e ao aporte nutritivo em relação ao que eram anteriormente. 
Desta forma, a pós-modernização, embalada pela globalização, tem imposto novas formas de consumo alimentar, tem afetado o nosso paladar e os aportes nutritivos, trazendo novos padrões alimentares, novos costumes, hábitos e práticas alimentares.

É a civilização McDonald's que se impõe. O fast-food é o principal fenômeno de consumo do mundo globalizado, é o ícone da globalização, sendo que o sanduíche de hambúrguer, a pizza, a batata frita e os refrigerantes (CocaCola) ganham a preferência, principalmente entre os jovens, quando o mais importante é a praticidade e a rapidez. As crianças também devem ser incluídas nesse grupo, sendo grandes consumidoras do McDonald's. Hoje, os alimentos são comprados quase prontos para o consumo, daí a grande procura por fornos microondas, congelados, pré-cozidos, pré-temperados e alimentos com empacotamento a vácuo. Essa praticidade e rapidez imposta pela sociedade contemporânea acabam derrubando as convenções ditas pela sociedade, construídas historicamente e pautadas pela tradição e pelos costumes. As refeições feitas em conjunto, em casa, com horário determinado e um cardápio planejado estão se tornando cada vez mais raras.

A sociedade de consumo em massa faz com que se desestruturem os sistemas normativos e os controles sociais que regiam tradicionalmente as práticas e as representações alimentares. Essas novas preferências alimentares, isto é, o hambúrguer, a pizza, a batata frita e a Coca-Cola, fazem com que haja a ascensão e a queda de alimentos. Hoje, no imaginário de muitos jovens, estar num McDonald's é se sentir no centro do mundo. Entretanto, as pesquisas mostram maior tendência à obesidade entre a população infantil. A propósito, devem ser consideradas duas obras importantes, dentre outras: Les Fils de McDo: la Mcdonalisation du Monde, de Paul Ariès, e País fast-food, de Eric Schlosser. Na primeira, Les Fils de Mcdo, o autor demonstra que o McDonald's constitui um verdadeiro feito da sociedade e não um fenômeno de moda ou de geração. Daí a tese de Ariès sobre a MacDonaldização do mundo, que, segundo ele, é extremamente preocupante porque cria um cosmopolitismo alimentar que se entende como universal. O autor chega a analisar a MacDonaldização do pensamento, do discurso, do corpo, da família, da mulher, da mãe e da criança. Na segunda, País fast-food, o autor busca explicar o que está por trás de um hambúrguer com fritas do McDonald's. Na obra, Schlosser conta a história da empresa, sendo que seu fundador, Ray Kroc, era um entusiasta do fordismo e introduziu, em seu primeiro MacDonald's, uma linha de montagem e uma rigorosa divisão de trabalho. $\mathrm{O}$ autor esmiúça os procedimentos nem sempre 
edificantes utilizados por essa indústria para atingir o máximo de eficiência e rentabilidade (ver filme Super Size me - a dieta do palhaço).

No Brasil, os estudos e pesquisas têm demonstrado que, em função do fast-food, um novo padrão alimentar está se delineando, com prejuízos dos produtos da dieta tradicional do povo. $\mathrm{O}$ arroz, o feijão, a farinha de mandioca, que foram, desde o século XVIII, a base do cardápio da maioria da população, perdem cada vez mais espaço para os produtos industrializados e com maior valor agregado. E não podemos esquecer que, em breve, teremos o ingresso dos alimentos transgênicos nessa competição. Pelos dados que temos, nos últimos 10 anos, o consumo anual de feijão caiu de $12 \mathrm{~kg}$ por brasileiro para $9,5 \mathrm{~kg}$. A farinha passou a ocupar o $38^{\circ}$ lugar no mercado alimentar. Em alguns estados, planta-se cada vez menos feijão. Isso tudo é muito ruim, principalmente para a população pobre.

No momento, estamos desenvolvendo pesquisa centrada na questão da preservação do patrimônio gustativo da sociedade curitibana, na qual os estudos apontam para as mesmas tendências acima apresentadas no tocante ao consumo de alimentos básicos. Os produtos originais e de qualidade estão em marcha lenta diante da invasão dos produtos estandartizados e banalizados propostos pela indústria agroalimentar a partir de um enorme sistema de marketing. Com o tempo, se tudo continuar assim, a oferta dos produtos mais tradicionais, originais e de qualidade, de gosto, vai diminuir sensivelmente.

O período analisado começa na conjuntura dos anos sessenta, em Curitiba, quando o processo de industrialização ainda era um pouco incipiente (ele se avolumaria a partir dos anos 70), e quando foram instalados os primeiros fast-foods. A partir dos anos 70, com o novo Plano Diretor de Curitiba e uma nova configuração do espaço territorial urbano, intensificou-se o processo de industrialização - promovido com base nas condições institucionais de intervenção do estado brasileiro -, aumentou a oferta de empregos, além de outras transformações ocorridas, fazendo surgir a Curitiba funcional, a Curitiba laboratório. Diante desse quadro e a partir daí - inclusive com a instalação dos supermercados -, partimos do pressuposto de que a alimentação começou a tornar-se um mercado de consumo em massa em Curitiba, distanciando-se, cada vez mais, do universo doméstico. Nesse sentido, diante das transformações dos controles sociais que pesaram e pesam sobre a alimentação, comer fora de casa se transformou em uma mercadoria e as preferências das pessoas deixaram de ser espontâneas, sendo geradas, também, por uma lógica econômica, o que implica numa mudança de comportamento, especialmente o alimentar. $\mathrm{O}$ balizamento final é o tempo presente (o tempo presente também é domínio do 
historiador), agora com as reações provenientes, dentre outras, da formatação de uma nova estética do corpo, tudo em nome da boa saúde.

A proposta de elaborar a presente pesquisa sobre uma "arca do sabor", no sentido de preservar o patrimônio gustativo da sociedade curitibana, inscreve-se, mais do que nunca, na conjuntura ou estrutura de domínio do fastfood. Esta pesquisa acadêmica se insere numa pesquisa maior, organizada pelo movimento denominado slow-food, de resistência ao fast-food (o slow-food é a comida devagar, tranqüila, contra o fast-food, que é a comida rápida). $\mathrm{O}$ slow-food é um movimento que começou na Itália em 1996, com a presença de mais de 10 países, e se espalhou pela Europa e por grande parte do mundo. Na América Latina, a Argentina tem forte representação. No Brasil, esse movimento praticamente não existe.

O slow-food é, portanto, um movimento internacional pela educação do gosto e pela biodiversidade alimentar. Ele reúne consumidores, produtores, jornalistas, representantes dos poderes públicos, diversas universidades e institutos de pesquisa e historiadores, que produzem trabalhos científicos que possam embasar a defesa da boa comida, dos produtos originais e de qualidade. Esse também é um compromisso da presente pesquisa.

No presente trabalho, que visa preservar o patrimônio gustativo da sociedade curitibana, os pratos, produtos e receitas que irão para a arca do sabor curitibano devem estar ligados a uma memória histórica e com identidade. Portanto, devem estar ligados ecologicamente, socioeconomicamente e historicamente a uma região precisa. A afirmação de que esses produtos devem ter história e tradição resulta do fato de que foram de grande aceitação, marcaram uma época, e hoje correm riscos reais ou potenciais de desaparecerem. Dentre outros objetivos dessa pesquisa, há também um objetivo prático: estimular a educação ao bom gosto e reforçar o direito ao prazer proporcionado pela boa comida.

Do exposto, é importante destacar algumas questões para serem respondidas ao longo da pesquisa: quais produtos, pratos e receitas poderiam entrar na arca do sabor para serem salvaguardados, promovidos e valorizados? A partir de quais critérios esses pratos e produtos seriam escolhidos? Como preservar a comida da alma? Comprometido com as consistências teóricometodológicas, o importante é ir às fontes, fazer entrevistas, identificar produtos. Algumas fontes podem, já, ser relacionadas: fontes de imprensa para o conhecimento da intensidade da divulgação dos pratos da cozinha compartimentada ao longo do período analisado, pois as preferências alimentares estão cada vez mais influenciadas pela publicidade; o acervo da 
Junta Comercial e da Associação Comercial, no tocante aos supermercados e à padronização das compras; os livros de receitas ou de cozinha de famílias curitibanas; os menus e cardápios de alguns restaurantes e bares da cidade; o acervo da Secretaria Municipal de Abastecimento, no tocante às feiras livres de Curitiba e ao Mercado Municipal; e as entrevistas (história oral) com agentes históricos importantes, como os proprietários de restaurantes, chefes de cozinha, cozinheiros e cozinheiras etc. Do exposto, é fundamental criar a arca do sabor e poder divulgá-la, pois deve representar um universo da memória gustativa.

\section{Referências}

ACKERMAN, Diane. Uma história natural dos sentidos. Rio de Janeiro: Bertrand Brasil, 1996.

AGUlHAN, Deborah. Das casas de pasto aos restaurantes: os sabores da velha Curitiba. Curitiba, 2005. Dissertação (Mestrado) - Universidade Federal do Paraná.

ALIMENTAÇÃO - ESTUDOS HISTÓRICOS. São Paulo: Fundação Getulio Vargas, n. 33, 2004.

ALLENDE, I. Afrodite - contos, receitas e outros afrodisíacos. Rio de Janeiro: Bertrand Brasil, 1998.

ALVES FILHO, Ivan; GIOVANNI, Roberto di. Cozinha brasileira com recheio de História. Rio de janeiro: Revan, 2000.

AMORIM, Suely T. S. P. Alimentação infantil e o marketing da indústria de alimentos: Brasil, 1960-1988. Curitiba, 2005. Tese (Doutorado) - Universidade Federal do Paraná.

ANDREAZZA, M. L.; NADALIN, S. O. Imigração e sociedade. Curitiba: UFPR, Departamento de História, 1993.

ARIÈS, Paul. Les fils de McDo: La McDonalisation du Monde. Paris: L'Harmattan, 1997.

ARMESTO, Felipe F. Comida: uma História. Rio de Janeiro: Record, 2004.

ARON, J. P. A cozinha: um cardápio do século XIX. In: LE GOFF, Jaques; NORA, Pierre (Eds.). História. Novos objetos. Rio de Janeiro: F. Alves, 1974. 
AVÉ-LALLEMANT, R. 1858, Viagem pelo Paraná / Robert Avé-Lallemant. Curitiba: Fundação Cultural, 1995.

BARROS, M. M. L. de. Memória e família. Estudos Históricos, Rio de Janeiro, v. 2, n. 3, p. 29-42, 1989.

BITENCOURT, Celia Cristina. Do gosto e do afeto: comida de imigrante - Curitiba 1900-1920. Curitiba, 2000. Dissertação (Mestrado) - Universidade Federal do Paraná.

BOLETIM INFORMATIVO DA CASA ROMÁRIO MARTINS. O cotidiano de Curitiba durante a II Guerra Mundial. Curitiba: Fundação Cultural de Curitiba, v. 22, n. 107 , out. 1995 .

BONIN, A. A.; ROLIM, M. do C. Hábitos alimentares: tradição e inovação. Boletim de Antropologia, Curitiba, v. 4, n. 1, p. 75-90, jun. 1991.

BORNHEIM, G. A. O conceito de tradição. In: BOSI, A. (Org.). Cultura brasileira: tradição/contradição. Rio de Janeiro: Zahar, 1987. p. 13-29.

BOSI, A. Cultura como tradição. In: _. (Org.). Cultura brasileira: tradição/ contradição. Rio de Janeiro: Zahar, 1987. p. 31-58.

BOSI, E. Memória e sociedade: lembrança de velhos. 2. ed. São Paulo: T.A. Queiroz; Edusp, 1987.

BOURDAIN, A. Cozinha confidencial: uma aventura nas entranhas da culinária. São Paulo: Cia. das Letras, 2001.

Em busca do prato perfeito. São Paulo: Cia. das Letras, 2003.

BRAUDEL, F. Bebidas y excitantes. Madrid: Alianza Editorial, 1994.

Civilização material e capitalismo. Lisboa: Cosmos, 1970.

La Mediterranée et le Monde Mediterranéen a l'époque de Phillippe II. Paris: Armand Colin, 1966.

BRILLAT-SAVARIN, Jean Anthelme. A fisiologia do gosto. São Paulo: Cia. das Letras, 1995.

CAMPORESI, P. Hedonismo e exotismo: a arte de viver na época das luzes. São Paulo: Ed. Unesp, 1996.

CANDIDO, A. Os parceiros do Rio Bonito - estudo sobre o caipira paulista e a transformação dos seus meios de vida. 4. ed. São Paulo: Duas Cidades, 1977.

CARNEIRO, H. Comida e sociedade: uma história da alimentação. Rio de Janeiro: Campus, 2003. 2005 .

Pequena enciclopédia da história das drogas e bebidas. São Paulo: Campus, 
CASCUDO, L. da C. História da Alimentação no Brasil. Belo Horizonte: Itatiaia, 1983.

CHAUI, Laura; CHAUI, Marilena S. Professoras na cozinha. São Paulo: Ed. Senac, 2001.

CIPOLLA, Joe. A cozinha da máfia. São Paulo: Ática, 1996.

COLLET, Emmanuel. Chocolat: de la Boisson Elitaire au Baton Populaire - XVIèmeXXème siecle. Bruxelas: CGER, 1996.

CUCHE, D. A noção de cultura nas Ciências Sociais. Bauru: Edusc, 1999. p. 179180.

DA MATTA, R. Sobre o simbolismo da comida no Brasil. O Correio, Rio de Janeiro, v. 15 , n. 7 , p. 22 , jul. 1987.

DEMETERCO, S. M. da S. Doces lembranças: cadernos de receitas e comensalidade. Curitiba 1900-1950. Curitiba, 1998. Dissertação (Mestrado em História) - Setor de Ciências Humanas, Letras e Artes da Universidade Federal do Paraná.

Sabor e saber: livros de cozinha e hábitos alimentares. Curitiba - 1902-1950. Curitiba, 2003. Tese (Doutorado em História) - Universidade Federal do Paraná.

DIAS LOPES, J. A. A canja do imperador. São Paulo: Cia. Ed. Nacional, 2004.

DUCROT, Victor E. Los sabores de la patria. Buenos Aires: Norma, 1998.

FERREIRA, M. de M.; AMADO, J. (Orgs.). Usos \& abusos da História Oral. Rio de Janeiro: Ed. FGV, 1996.

FERREIRA, M. de M.; FERNANDES, T. M.; ALBERTI, V. (Orgs.). História Oral: desafios para o século XXI. Rio de Janeiro: Fiocruz, 2000.

FISCHLER, Claude. L'Homnivore. Paris: O. Jacob, 1990.

FLANDRIN, Jean Louis. A distinção pelo gosto. In: ARIES, P.; CHARTIER, R. História da vida privada: da Renascença ao Século das Luzes. São Paulo: Cia. das Letras, 1991.

FLANDRIN, Jean-Louis; MONTANARI, Massimo. História da Alimentação. São Paulo: Estação Liberdade, 1998.

FRANCATELLI, Charles E. Um simples livro de culinária para as classes trabalhadoras. São Paulo: Angra, 2001.

FRANCO, Ariovaldo. De caçador a gourmet: uma história da gastronomia. São Paulo: Ed. Senac, 2001.

FRAZÃO, Márcia. A panela de Afrodite. Rio de janeiro: Bertrand Brasil, 2000.

FREI BETTO. Comer como um frade: divinas receitas para quem sabe por que tem um céu na boca. Rio de Janeiro: J. Olympio, 2003. 
FREYRE, Gilberto. Açúcar. São Paulo: Cia. das Letras, 1997.

GEERTZ, C. A interpretação da cultura. Rio de Janeiro: Zahar, 1978.

GIARD, L. Cozinhar. In: CERTEAU, M. de. A invenção do cotidiano - morar, cozinhar. Petrópolis: Vozes, 1996. p. 211-332.

GRIECO, A. F. Alimentação e classes sociais no fim da Idade Média e na Renascença. In: FLANDRIN, J.; MONTANARI, M. História da Alimentação. São Paulo: Estação Liberdade, 1998. p. 466-477.

HALBWACHS, Maurice. A memória coletiva. São Paulo: Vértice, 1990.

HALL, Stuart. A identidade cultural na pós-modernidade. Rio de Janeiro: DP\&A, 1999.

HOBSBAWM, Eric; RANGER, Terence (Org.). A invenção das tradições. 2. ed. Rio de Janeiro: Imago, 1997.

HORTA, L. (Org.). O melhor da gastronomia e do bem viver. São Paulo: DBA Artes Gráficas, 2004

HORTA, Nina. Não é sopa: crônicas e receitas de comida. São Paulo: Cia. das Letras, 1995.

JACOB, Heinrich E. Seis mil anos de pão: a civilização humana através de seu principal alimento. São Paulo: Ed. Nova Alexandria, 2003.

JOHNSON, H. A história do vinho. São Paulo: Cia. das Letras, 1999.

L'Atlas Mondial du Vin. Paris: R. Laffont, 1985.

KURLANSKY, Mark. Sal: uma história do mundo. São Paulo: Ed. Senac, 2004.

LACERDA, Maria Thereza B. Café com mistura. Curitiba: Imprensa Oficial, 2002.

LE GOFF, J. História e memória. 4. ed. Campinas: Ed. Unicamp, 1996.

LE GOFF, J.; NORA, P. História, novas abordagens. Rio de Janeiro: F. Alves, 1974.

_. História, novos objetos. Rio de Janeiro: F. Alves, 1974.

; ___ História, novos problemas. Rio de Janeiro: F. Alves, 1974.

LEONARDO DA VINCI. Os cadernos de cozinha de Leonardo da Vinci. Rio de Janeiro: Record, 2002.

LINHARES, T. História econômica do mate. Rio de Janeiro: J. Olympio, 1969.

Paraná vivo: um retrato sem retoques. Rio de Janeiro: J. Olympio, 1953.

MAGALHÃES, M. B. Pangermanismo e nazismo - a trajetória alemã rumo ao Brasil. Campinas: Unicamp/Fapesp, 1998. p. 19. 
MARENCO, Claudine. Manières de table, modèles de moeurs - 17ème/20ème siècle. Cachan: ENS, 1992.

MARTINS, W. Um Brasil diferente - ensaio sobre fenômenos de aculturação no Paraná. 2. ed. São Paulo: T. A. Queiroz, 1989.

MAURIZIO, Adam. Histoire de l'Alimentation végétale depuis la préhistoire jusqu'à nous jours. Paris: Payot, 1932.

MELO, Josimar. A cerveja. São Paulo: PubliFolha, 2000.

Berinjela se escreve com J. São Paulo: DBA, 1999.

MENESES, U. T. B.; CARNEIRO, H. A História da Alimentação: balizas historiográficas. Anais do Museu Paulista - História e Cultura Material, São Paulo, v. 5, p. 9-91, jan./dez. 1997.

PILLA, Maria Cecília A. A arte de receber: distinção e poder à boa mesa (1900-1970). Curitiba, 2004. Tese (Doutorado) - Departamento de História, Universidade Federal do Paraná.

PITTE, Jean-Robert. Gastronomie Française: histoire et geographie d'une passion. Paris: Fayard, 2001.

POLLAK, M. Memória, esquecimento, silêncio. Estudos Históricos, Rio de Janeiro, v. 2, n. 3, p. 3-15, 1989.

Memória e identidade social. Estudos Históricos, Rio de Janeiro, v. 5, n. 10, p. $\overline{200-2} 12,1992$.

PROUST, M. Em busca do tempo perdido - o caminho de Swann. 15. ed. São Paulo: Globo, 1993. 1995.

Em busca do tempo perdido - o tempo redescoberto. 12. ed. São Paulo: Globo,

QUEIROZ, R. de. O não me deixes - suas histórias e sua cozinha. São Paulo: Siciliano, 2000.

R. C. M. O cozinheiro imperial. São Paulo: Best Seller, 1996.

REINHARDT, Juliana. $O$ pão nosso de cada dia: a Padaria América e o pão das gerações curitibanas. Curitiba, 2002. Dissertação (Mestrado em História) - Setor de Ciências Humanas, Letras e Artes da Universidade Federal do Paraná.

REVEL, J. Um banquete de palavras - uma história da sensibilidade gastronômica. São Paulo: Cia. das Letras, 1996.

RODRIGUES, A. G. Comida típica - comida ritual. In: REUNIÃO BRASILEIRA DE ANTROPOLOGIA, 23., jul. 2002, Gramado. Resumos... Gramado, 2002. 
ROLIM, M. C. M. B. Gosto, prazer e sociabilidade - bares e restaurantes de Curitiba, 1950-1960. Curitiba, 1997. Tese (Doutorado em História) - Setor de Ciências Humanas, Letras e Artes da Universidade Federal do Paraná.

RORIZ, R. Cultura e modernidade-mundo. In: . Mundialização e cultura. São Paulo: Brasiliense, 1994. p. 71-87.

ROSS, Ciro B. Eu sou o Chef. Niterói: Casa Jorge Editorial, 1996.

SANTOS, A. C. de A. Memórias e cidade - depoimentos e transformação urbana de Curitiba (1930-1990). 2. ed. Curitiba: Aos Quatro Ventos, 1997.

SANTOS, C. R. A. dos. História da Alimentação no Paraná. Curitiba: Fundação Cultural, 1995.

Paraná: vida material, vida econômica. Curitiba: SEED, 2001.

Por uma História da Alimentação. História, Questões \& Debates, Curitiba, n. 26-27, p. 154-171, 1997.

SANTOS, Sergio de Paula. Vinho e História. São Paulo: DBA, 1998.

SAUCEDO, Daniele R. Do privado ao público: o universo do restaurante Bolonha. Curitiba, 2002. Dissertação (Mestrado em História) - Setor de Ciências Humanas, Letras e Artes da Universidade Federal do Paraná

SCHINEIDER, Claides. Do cru ao assado: a Festa do Boi Assado no Rolete de Marechal Cândido Rondon. Curitiba, 2002. Dissertação (Mestrado em História) - Setor de Ciências Humanas, Letras e Artes da Universidade Federal do Paraná.

SCHLOSSER, Eric. País fast-food: o lado nocivo da comida americana. São Paulo: Ática, 2001.

SCHWINDEN, Antônia. Leão Junior S. A. Empresa centenária. Curitiba: Leão Junior S.A., 2001.

SGANZERLA, E.; STRASBURGER, J. Culinária paranaense. Curitiba: Esplendor, 2004.

SOLE, Orieta del. Nunca treze à mesa. São Paulo: Cia. das Letras, 1997.

SPANG, Rebecca L. A invenção do restaurante. Rio de Janeiro: Record, 2003.

STEINGARTEN, J. O homem que comeu de tudo. São Paulo. Cia. das Letras, 2000.

STRONG, R. Banquete: uma história ilustrada da culinária, dos costumes e da fartura à mesa. Rio de Janeiro: J. Zahar, 2004.

THOMPSON, P. A transmissão cultural entre gerações dentro das famílias: uma abordagem centrada em histórias de vida. Ciências Sociais Hoje, ANPOCS, p. 9-19, 1993. 
A voz do passado - história oral. Rio de Janeiro: Paz e Terra, 1992.

URBAN, Raul G. Curitiba: lares e bares: viagens pelas histórias e estórias nos dias e noites dos bares e afins de Curitiba. Curitiba, Univer Cidade, 2002.

VICTOR, N. A terra do futuro - impressões do Paraná. Rio de Janeiro: Typ. do "Jornal do Commercio", 1913. p. 99.

VISSER, Margareth. O ritual do jantar. Rio de Janeiro: Campus, 1998.

WOLKE, Robert L. O que Einstein disse ao seu cozinheiro. Rio de Janeiro: Zahar, 2003.

WOORTMANN, K. A comida, a família e a construção do gênero feminino. Revista de Ciências Sociais, Rio de Janeiro, v. 29, n. 1, 1986. 